\title{
Simulating the Transfer of Strontium-90 from Soil to Leafy Vegetables by Using Strontium-88
}

\author{
Ding Kuke • Liu Shujuan • He Yingxue • Yan Dong • \\ Zhang Fengshou • Wang Shuifeng • Guo Jinghua • \\ Zhang Wei • Wang Xin • Jiang Xiaoyan
}

Received: 24 May 2016/Accepted: 20 September 2016/Published online: 25 October 2016

(C) The Author(s) 2016. This article is published with open access at Springerlink.com

\begin{abstract}
The transfer, from soil to Chinese cabbage and spinach, of radioactive strontium-90 released as a result of accidents in nuclear power stations was studied using a stable isotope of strontium, namely nuclide strontium- $88\left({ }^{88} \mathrm{Sr}\right)$. The study led to an experimental model for assessing the hazard of radionuclide strontium-90 $\left({ }^{90} \mathrm{Sr}\right)$ entering the food chain and for predicting the risk to food safety. Chinese cabbage and spinach were grown in pots in a greenhouse and irrigated with deionized water containing known quantities of strontium. Based on the strontium content of that water, the plants were divided into five groups (treatments) and strontium content of the soil, and 30-day-old plants were determined by inductively coupled plasma atomic
\end{abstract}

D. Kuke $(\bowtie) \cdot$ L. Shujuan $\cdot$ H. Yingxue $\cdot$ Y. Dong $\cdot$

Z. Wei $\cdot$ W. Xin $\cdot$ J. Xiaoyan $(\bowtie)$

Department of Radiology, National Institue for Radiological

Protection, Chinese Center for DiseaseControl and Prevention,

Beijing 100088, China

e-mail: ding1128@sina.com

e-mail: shouding@ccmu.edu.cn

D. Kuke $\cdot$ L. Shujuan $\cdot$ H. Yingxue $\cdot$ Y. Dong $\cdot$ Z. Wei $\cdot$ W. Xin · J. Xiaoyan

Key Laboratory of Radiological Protection and Nuclear

Emergency, Chinese Center for Disease Control and Prevention,

Beijing 100088, China

\section{Z. Fengshou}

College of Nuclear Science and Technology, Beijing Normal

University, Beijing 100875, China

W. Shuifeng · G. Jinghua

Analytical and Testing Center, Beijing Normal University,

Beijing 100875, China emission spectroscopy instrument (ICP-AES). Data on the strontium content of soil and plants enabled the development of a model using MATLAB, a mathematical software package, which included curve fitting and problem solving using regression equations and differential equations. Although strontium curves for leaves, stems, and roots of Chinese cabbage were not exactly the same, all showed a non-linear increase when compared with the increase in the content of strontium in soil. Strontium curves for leaves, stems, and roots of spinach were very similar and showed an initial increase followed by a decrease. Strontium concentrations in both Chinese cabbage and spinach were initially related to the concentrations of sodium and sulfur, the next two relevant nuclides being calcium and magnesium. The relationship between calcium and strontium in Chinese cabbage was different from that in spinach. By using ${ }^{88} \mathrm{Sr}$ to simulate the transfer of radionuclide ${ }^{90} \mathrm{Sr}$ from soil to a crop, the relevant data required to deal with accidental release of strontium can be obtained using a fitting curve and regression equations, thereby providing some experimental basis for evaluating the potential hazards posed by such accidents to the food chain.

Keywords Chinese cabbage $\cdot$ Spinach $\cdot{ }^{90} \mathrm{Sr} \cdot{ }^{88} \mathrm{Sr}$. Fitting curve

A common product of fission that occurs during accidents in nuclear power stations is strontium- $90\left({ }^{90} \mathrm{Sr}\right)$. As an element, strontium has 17 different isotopes, ranging from strontium-81 to strontium-97, of which 
strontium- $89\left({ }^{89} \mathrm{Sr}\right)$ and strontium- $90\left({ }^{90} \mathrm{Sr}\right)$ are particularly toxic. Average energy of $\beta$-particles emitted by ${ }^{89} \mathrm{Sr}$ is higher than the ones emitted by ${ }^{90} \mathrm{Sr}$, but the former radioelement has a shorter half-life (50.57 days) than the latter (28.79 years). Whatever the cause, once radioactive strontium is released into the environment, it is likely to enter the human body through food and drinking water (Mollah et al. 1998; Choi et al. 2009). Once ingested, it is difficult to remove radioactive strontium from the body, and internal exposure to radionuclides can have disastrous consequences for human life.

As nuclear power finds wider applications, the background values of radioactive elements continue to increase steadily. As stated in the Evaluation Report on the Environmental Quality of China's Nuclear Industry for 30 years, average emissions of ${ }^{90} \mathrm{Sr}$ are $4.2 \times 10^{7} \mathrm{~Bq}$ a year. These radioactive elements can be absorbed by plant roots through soil and by leaves through air. Consumption of such contaminated vegetables is harmful to health and may even lead to different forms of cancer. Once the radioactive elements, including ${ }^{90} \mathrm{Sr}$, enter the environment (as a result of accidents in nuclear power facilities or by any other means), they are a threat to public health, both physical and mental, and to food safety. Therefore, the Chinese government has paid close attention to exploring the techniques of dealing with nuclear accidents and emergencies and has also focused on the transmission of radioactive elements to soil and water and, through soil and water thus enriched, to food and, ultimately, to people.

Stable nuclides and radioactive nuclides have identical chemical properties and biological characteristics, and scientists have used stable nuclides instead of radioactive nuclides in research, which served to confirm the significant correlation between the two kinds of nuclides. Many studies on radioactive strontium are based on the stable form of strontium (Höllriegl et al. 2002; James et al. 2011). In keeping environmental concerns and the needs of field testing in mind, use of the stable form of strontium instead of the radioactive form (Tatiana et al. 2010) is acceptable in both theory and practice. Accordingly, we chose to explore the path of radioactive ${ }^{90} \mathrm{Sr}$ from soil to the crop by using the stable form, namely ${ }^{88} \mathrm{Sr}$.

As most of our food comes from plants, the present study not only provides a theoretical basis and technical support for monitoring and evaluating food safety after any accidents involving radioactive material but also helps the government in instilling confidence in people during such accidents and in dealing more effectively with the fallout of radioactive material and with the ensuing contamination of vegetables.

\section{Materials and Methods}

\subsection{Materials}

The plants used in this study were all grown in a greenhouse in Xingshou, in Changping district of Beijing. Topsoil was used for growing Chinese cabbage and spinach, the seeds of which were bought from Beijing Zhongshu Horticultural Seed Research Center, Chinese Academy of Agricultural Sciences. In addition, $\mathrm{SrCl}_{2} \cdot 6 \mathrm{H}_{2} \mathrm{O}$, the source of the ${ }^{88} \mathrm{Sr}$, was produced by Sinopharm Chemical Reagent Company, Shanghai city, China. After calculating the doses of ${ }^{88} \mathrm{Sr}$ and $\mathrm{SrCl}_{2} \cdot 6 \mathrm{H}_{2} \mathrm{O}$, deionized water was used to dissolve the required $\mathrm{SrCl}_{2} \cdot 6 \mathrm{H}_{2} \mathrm{O}$ and applied to the experimental soil.

\subsection{Pot Experiment}

After removing small stones and other debris from the experimental topsoil, it was air-dried in shade and pulverized fine enough to pass through a 30-mesh sieve $(0.595 \mathrm{~mm})$. Every pot was filled with $2 \mathrm{~kg}$ of soil, the required quantity of strontium was added, and the pots were placed in shade for 2 weeks to ensure stable conditions. Six seeds were sown in each pot.

\subsection{Treatments}

Chinese cabbage and spinach were grown under the same experimental conditions, including water content of soil maintained at $70 \%$ and irrigation with deionized water. The greenhouse not only protected the plants from wind, sand, insect pests, and rain, but also maintained a relatively stable experimental environment. Seedlings were collected for analysis 30 days after sowing.

\subsection{Analysis of Samples}

\subsubsection{Processing of Soil Samples}

Samples of soil from the pots were air-dried and ground fine enough to pass through a 100-mesh sieve 
$(0.149 \mathrm{~mm})$. The soil samples $(0.1 \mathrm{~g}$ each $)$ were weighed and placed in polytetrafluoroethylene cans. After adding $6 \mathrm{~mL}$ of $\mathrm{HNO}_{3}$ and $2 \mathrm{~mL}$ of $\mathrm{HF}$ (hydrofluoric acid), the samples were digested by keeping them in a microwave digestion instrument. After the samples had cooled to room temperature, the cans were taken out from the digestion instrument, and $1 \mathrm{~mL}$ of perchloric acid was added to each sample. Next, the samples were concentrated to a very small volume by heating over a plate heater to remove excess acid; the residue was dissolved in highly pure deionized water; and the contents were transferred to $10-\mathrm{mL}$ flasks. Strontium concentration in soil was determined using a spectrograph (SPECTROBLUE ICP-AES, SPECTRO ARCOS, KLEVE city, Germany). As controls, blanks with the same amounts of acid were processed in the same manner except for adding no strontium earlier.

\subsubsection{Processing of Plant Samples}

Thirty-day-old seedlings of the two vegetables were collected from the greenhouse, washed with deionized water, air-dried, and packed in hydrochloric acid treatment weighing bottles before drying at $80{ }^{\circ} \mathrm{C}$ and then ground at room temperature. The samples (0.2 g each, weighed on digital weighing scales) were placed in polytetrafluoroethylene cans and processed the same way as described above for soil samples (Section 1.4.1). For the controls of plant samples, the blanks with the same amounts of acid were processed in the same manner except for adding no strontium earlier.

\section{Results and Analysis}

2.1 Greenhouse Soil and Concentration of Strontium in Deionized Water

Generally, both soil and irrigation water contain strontium. Although we use deionized water to irrigate the vegetables, we determined the initial content of strontium in the soil and in deionized water (Table 1).

2.2 Concentrations of ${ }^{88} \mathrm{Sr}$ and $\mathrm{SrCl}_{2} \cdot 6 \mathrm{H}_{2} \mathrm{O}$ in Soil After Addition of ${ }^{88} \mathrm{Sr}$

The experiment comprised four treatments-based on the dose of strontium - and a control group (strontium 
0 ). The concentrations of ${ }^{88} \mathrm{Sr}$ and $\mathrm{SrCl}_{2} \cdot 6 \mathrm{H}_{2} \mathrm{O}$ in each group are shown in Table 2. The concentration (C) of strontium was calculated as follows: $\mathrm{C}=(\mathrm{C} 1 \times \mathrm{M}+$ $99.8 \% \times 88 / 267 \times \mathrm{X}) /(\mathrm{M}+\mathrm{X})$, where $\mathrm{C} 1$ is the initial concentration of strontium in soil, $\mathrm{M}$ is the weight of the original soil $\left(2 \times 10^{6} \mathrm{mg}\right)$, and $\mathrm{X}$ is the amount of $\mathrm{SrCl}_{2} \cdot 6 \mathrm{H}_{2} \mathrm{O}$ (99.8\% pure).

\subsection{Plant Samples}

All the samples - Chinese cabbage, spinach, and soilwere collected and processed at the same time.

Plant samples were separated into above-ground parts and below-ground parts. After determining some elements in the samples, a mathematical model was constructed of the pattern of strontium transfer from soil to Chinese cabbage and spinach based on appropriate fitting equations and differential equations governing the transfer. In addition, the correlation between strontium and other nuclides was also analyzed to ascertain the other elements involved in the transfer of strontium to provide a direct experimental basis for the internal mechanism of strontium transfer.

To construct a better mathematical model, MATLAB, a mathematical software package, was used. MATLAB is a business mathematics software developed by MathWorks (Natick, Massachusetts, USA) and includes Simulink. In the present study, the experimental data were fitted into the equations by using MATLAB's partial differential toolbox, and the relationship among these elements was analyzed by its statistics toolbox.

2.4 Construction of the Fitting Curve and Regression Equations

\subsubsection{Transfer Pattern of Strontium from Soil to Chinese Cabbage Leaves}

Experimental data were used for fitting the curve (seven times polynomial fitting was selected), as shown in Fig. 1. The horizontal axis represents strontium concentration in the soil in which Chinese cabbage was grown (micrograms of strontium per gram of soil), and the vertical axis represents strontium content of leaves of Chinese cabbage (micrograms of strontium per gram of dry leaves). The regression equation was then constructed using MATLAB.

The regression equation for the above curve is as follows:

$$
\begin{aligned}
\mathrm{y}= & (47,289 \times \mathrm{x}) / 10-\left(26,551 \times \mathrm{x}^{2}\right) / 1000+\left(1,998,733,543,424,045 \times \mathrm{x}^{3}\right) \\
& / 72,057,594,037,927,936+\left(2,688,889,649,904,273 \times \mathrm{x}^{4}\right) / 9,223,372,036,854,775,808-\left(5,961,043,211,326,353 \times \mathrm{x}^{5}\right) \\
& / 4,722,366,482,869,645,213,696+\left(4,865,442,853,621,037 \times \mathrm{x}^{6}\right) / 2,417,851,639,229,258,349,412,352- \\
& \left(1,447,028,111,920,681 \times \mathrm{x}^{7}\right) / 1,237,940,039,285,380,274,899,124,224-281,655
\end{aligned}
$$

The differential equation for the above regression equation is as follows:

$$
\begin{aligned}
\text { Dy } / \mathrm{dx} & =\left(5,996,200,630,272,135 \times \mathrm{x}^{2}\right) / 72,057,594,037,927,936-(26,551 \times \mathrm{x}) / 500+\left(2,688,889,649,904,273 \times \mathrm{x}^{3}\right) / \\
& 2,305,843,009,213,693,952-\left(29,805,216,056,631,765 \times \mathrm{x}^{4}\right) / 4,722,366,482,869,645,213,696+ \\
& \left(14,596,328,560,863,111 \times \mathrm{x}^{5}\right) / 1,208,925,819,614,629,174,706,176-\left(10,129,196,783,444,767 \times \mathrm{x}^{6}\right) / \\
& 1,237,940,039,285,380,274,899,124,224+47,289 / 10
\end{aligned}
$$


Table 2 Experimental amount of ${ }^{88}$ strontium and $\mathrm{SrCl}_{2} \cdot 6 \mathrm{H}_{2} \mathrm{O}$

\begin{tabular}{lllll}
\hline $\begin{array}{l}\text { Experiment } \\
\text { group }\end{array}$ & $\begin{array}{l}\text { Relationship with the original } \\
\text { strontium in the soil }\end{array}$ & $\begin{array}{l}\text { Concentration of strontium } \\
(\mathrm{mg} / \mathrm{kg})\end{array}$ & $\begin{array}{l}\text { Amount of } \\
88 \text { strontium }(\mathrm{mg})\end{array}$ & $\begin{array}{l}\text { Amount of strontium Cl2 } \\
6 \mathrm{H} 2 \mathrm{O}(\mathrm{mg})\end{array}$ \\
\hline Strontium0 & 1.0 times & 318.67 & 0.00 & 0.00 \\
Strontium1 & 1.5 times & 478.00 & 159.33 & 484.75 \\
Strontium2 & 2.0 times & 637.33 & 318.67 & 969.74 \\
Strontium3 & 2.5 times & 796.67 & 478.00 & 1454.96 \\
Strontium4 & 3.0 times & 956.00 & 637.33 & 1940.42 \\
\hline
\end{tabular}

\subsubsection{Transfer Pattern of Strontium from Soil to Chinese Cabbage Roots}

As described in Section 2.4.1, the initial content of strontium in soil was plotted on the horizontal axis; the content of strontium in below-ground parts of Chinese cabbage was plotted on the vertical axis; and the experimental data were used for fitting the curve (Fig. 2). The regression equation was then constructed using MATLAB.

The regression equation for the above curve is as follows:

\footnotetext{
$y=\left(3,127 \times x^{2}\right) / 5-64,041 \times x-\left(2,073 \times x^{3}\right) / 625+\left(742,985,852,125,075 \times x^{4}\right) / 72,057,594,037,927,936-$

$\left(2,770,553,385,918,585 \times x^{5}\right) / 147,573,952,589,676,412,928+\left(1,399,633,867,658,837 \times x^{6}\right) /$

$75,557,863,725,914,323,419,136-\left(4,727,197,834,015,153 \times x^{7}\right) / 618,970,019,642,690,137,449,562,112+2,748,900$
}

Fig. 1 Fitting curve of strontium from soil to the stem and leaf of Chinese cabbage

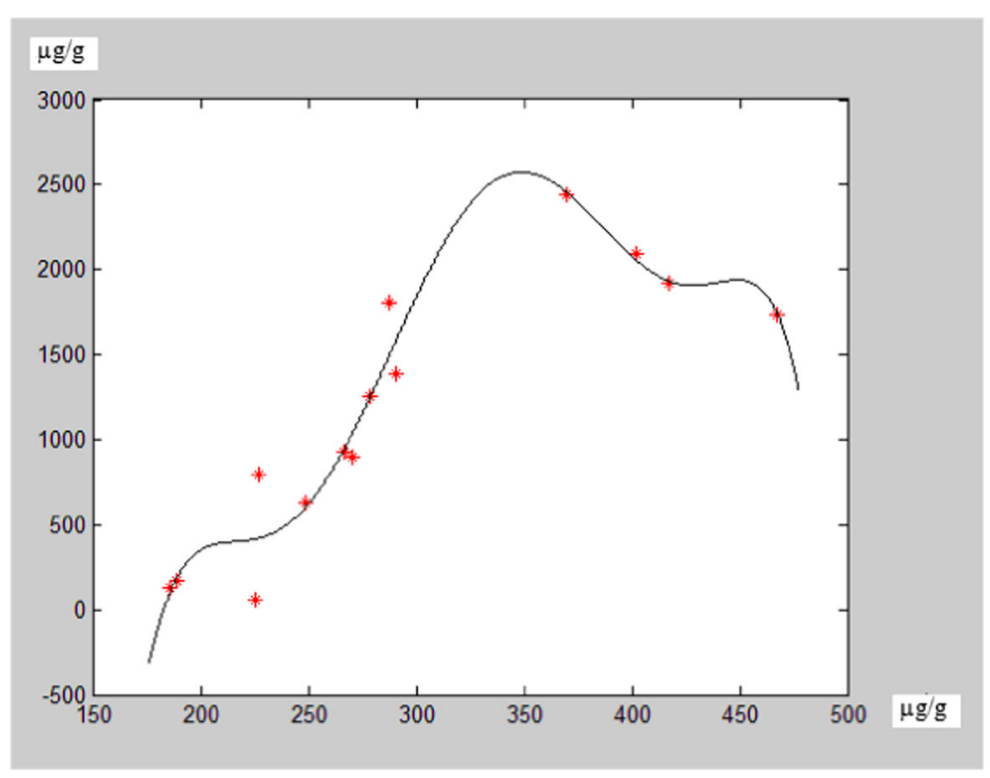


Fig. 2 Fitting curve of strontium from soil to the root of the Chinese cabbage

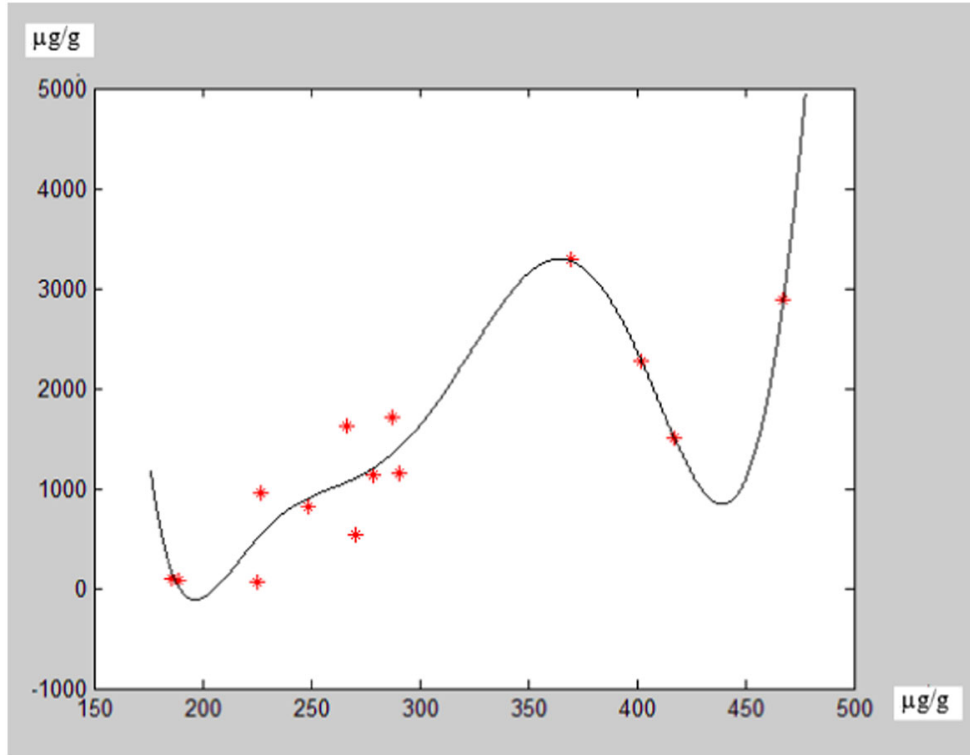

The differential equation for the above regression equation is as follows:

$\mathrm{dy} / \mathrm{dx}=(6,254 \times \mathrm{x}) / 5-\left(6,219 \times \mathrm{x}^{2}\right) / 625+\left(742,985,852,125,075 \times \mathrm{x}^{3}\right) / 18,014,398,509,481,984-$

$\left(13,852,766,929,592,925 \times x^{4}\right) / 147,573,952,589,676,412,928+\left(4,198,901,602,976,511 \times x^{5}\right) /$

$37,778,931,862,957,161,709,568-\left(33,090,384,838,106,071 \times x^{6}\right) / 618,970,019,642,690,137,449,562,112-64,041$

\subsubsection{Transfer Pattern of Strontium from Soil to Spinach} Stems and Leaves

As described in Section 2.4.1, the initial content of strontium in soil was plotted on the horizontal axis; the content of strontium in the above-ground parts of spinach was plotted on the vertical axis; and the experimental data were used for fitting the curve (Fig. 3). The regression equation was then constructed using MATLAB.

The regression equation for the above curve is as follows:

$\mathrm{y}=\left(1,359 \times \mathrm{x}^{2}\right) / 40-(16,934 \times \mathrm{x}) / 5-\left(1,147 \times \mathrm{x}^{3}\right) / 6,250+\left(5,316,351,642,043,093 \times \mathrm{x}^{4}\right) /$

$9,223,372,036,854,775,808-\left(4,968,874,013,275,441 \times x^{5}\right) / 4,722,366,482,869,645,213,696+(1,250,391,975,227,411$ $\left.\times \mathrm{x}^{6}\right) / 1,208,925,819,614,629,174,706,176-\left(4,188,000,670,504,013 \times \mathrm{x}^{7}\right) / 9,903,520,314,283,042,199,192,993,792+$ 140,277 
Fig. 3 Fitting curve of strontium from soil to the stem and leaf of spinach

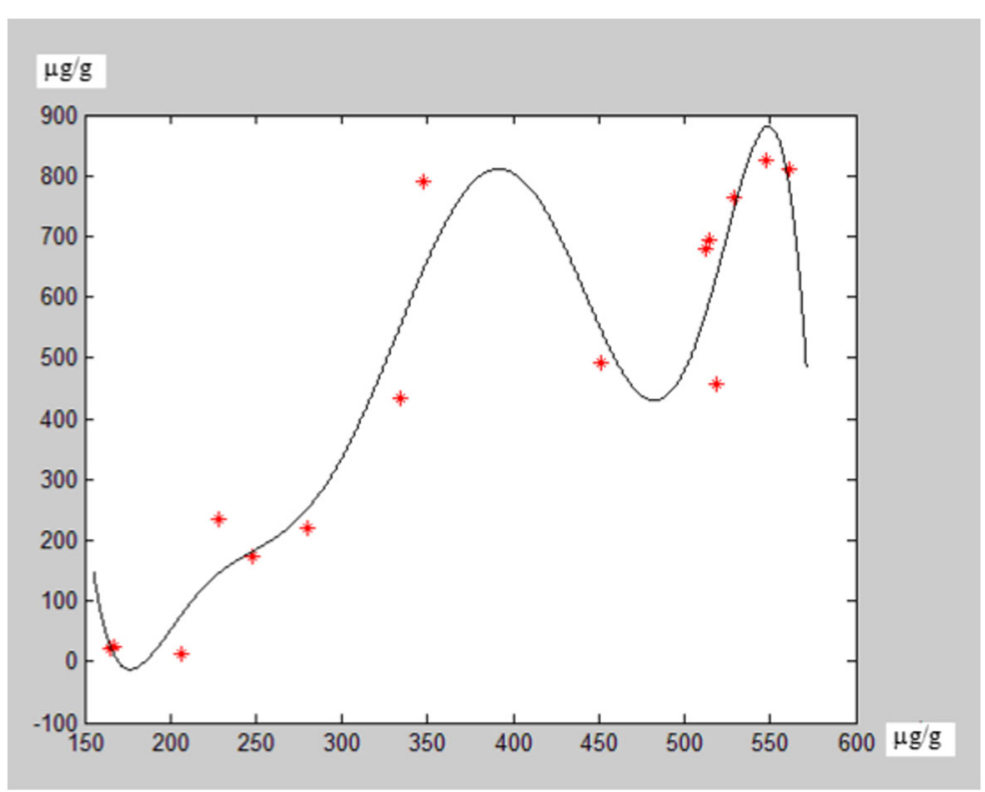

The differential equation for the above regression equation is as follows:

$\mathrm{dy} / \mathrm{dx}=(1,359 \times \mathrm{x}) / 20-\left(3,441 \times \mathrm{x}^{2}\right) / 6,250+\left(5,316,351,642,043,093 \times \mathrm{x}^{3}\right) / 2,305,843,009,213,693,952-$ $\left(24,844,370,066,377,205 \times x^{4}\right) / 4,722,366,482,869,645,213,696+\left(3,751,175,925,682,233 \times x^{5}\right) /$ $604,462,909,807,314,587,353,088-\left(29,316,004,693,528,091 \times x^{6}\right) / 9,903,520,314,283,042,199,192,993,792-16,934$ / 5

\subsubsection{Transfer Pattern of Strontium from Soil to Spinach Roots}

As described in Section 2.4.1, the initial content of strontium in the soil was plotted on the horizontal axis; the content of strontium in the below-ground parts of spinach was plotted on the longitudinal axis; and the experimental data were used for fitting the curve (Fig. 4). The regression equation was then constructed using MATLAB.

The regression equation for the above curve is as follows:

$y=\left(21,929 \times x^{2}\right) / 500-4,408 \times x-\left(5,873 \times x^{3}\right) / 25,000+\left(6,748,372,384,485,165 \times x^{4}\right) / 9,223,372,036,854,775,808$ - $\left(6,257,607,826,450,567 \times x^{5}\right) / 4,722,366,482,869,645,213,696+\left(3,126,765,739,851,277 \times x^{6}\right) /$ $2,417,851,639,229,258,349,412,352-\left(5,202,418,256,296,025 \times x^{7}\right) / 9,903,520,314,283,042,199,192,993,792+$ 184,055 
Fig. 4 Fitting curve of strontium from soil to the root of the spinach

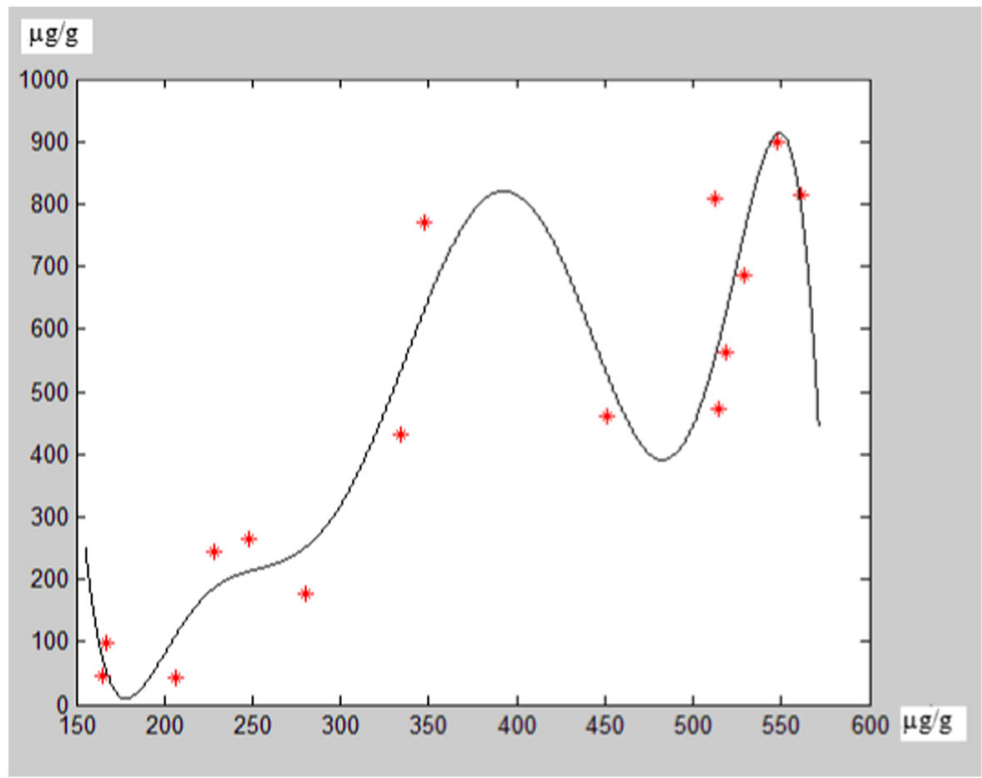

The differential equation for the above regression equation is as follows:

$\mathrm{dy} / \mathrm{dx}=(21,929 \times \mathrm{x}) / 250-\left(17,619 \times \mathrm{x}^{2}\right) / 25,000+\left(6,748,372,384,485,165 \times \mathrm{x}^{3}\right) / 2,305,843,009,213,693,952-$ $\left(31,288,039,132,252,835 \times x^{4}\right) / 4,722,366,482,869,645,213,696+\left(9,380,297,219,553,831 \times x^{5}\right) /$ $120,892,5819,614,629,174,706,176-\left(36,416,927,794,072,175 \times x^{6}\right) / 9,903,520,314,283,042,199,192,993,792-4,408$

2.5 Correlation Between Strontium and Other Elements in Spinach and Chinese Cabbage

To better understand the influence of other elements on strontium accumulation in spinach and Chinese cabbage, we analyzed the correlation between the contents of different elements and the strontium concentrations in above-ground plant parts (Table 3), represented here as $\delta$ : the closer its absolute value to 1 , the greater the correlation, and the closer its absolute value to 0 , the lower the correlation. Positive values of $\delta$ mean a positive correlation between the two elements, and negative values mean a negative correlation.

As shown in Table 3, the elements with closer correlation to strontium in the above-ground parts were $\mathrm{Na}$, $\mathrm{S}$, and $\mathrm{Ca}$. $\mathrm{Na}$ and $\mathrm{S}$ were negatively correlated to strontium in the stem and leaves of Chinese cabbage, and $\mathrm{Ca}$ was negatively correlated to strontium in the stems and leaves of spinach. These observations may indicate that the negative correlation between $\mathrm{Ca}$ and strontium also depends on the kind of vegetable: for example, in roots of the Chinese cabbage and spinach, the elements with closer correlation to strontium were $\mathrm{Ca}$ and $\mathrm{Mg}$, with $\mathrm{Ca}$ showing a closer correlation. In other words, $\mathrm{Ca}$ counters the build-up on strontium in Chinese cabbage and spinach.

\section{Discussion}

In the wake of several accidents in nuclear power plants, which have had disastrous consequences, the pattern of transfer of radioactive nuclides from soil to plants has received considerable attention. The soil and plants from such contaminated regions have been analyzed, and one of the outcomes is the transfer index of radioactive nuclides (Tolstykh et al. 2013). The affected countries-Ukraine, the United States, the former Soviet 
Table 3 Correlation value $(\delta)$ between strontium and other elements in two kinds of vegetable

\begin{tabular}{llllllll}
\hline$\Delta$ value & $\mathrm{Ca}$ & $\mathrm{Fe}$ & $\mathrm{K}$ & $\mathrm{Mg}$ & $\mathrm{Na}$ & $\mathrm{P}$ & $\mathrm{S}$ \\
\hline Stem and leaf of Chinese cabbage & -0.19778 & 0.1127 & -0.12741 & -0.12866 & -0.35877 & -0.049859 & -0.32887 \\
Root of Chinese cabbage & 0.60962 & 0.15903 & -0.22287 & 0.4057 & 0.11456 & -0.23418 & -0.2728 \\
Stem and leaf of spinach & 0.18658 & 0.012704 & -0.051571 & -0.26912 & -0.33307 & -0.11188 & -0.54219 \\
Root of spinach & 0.51805 & -0.27108 & 0.16023 & -0.41274 & -0.14371 & 0.19908 & 0.014272 \\
\hline
\end{tabular}

Union, and Japan — have developed suitable experimental sites for such studies. However, countries that do not have such experimental sites, such as China (unless they use a site at which nuclear weapons have been tested), should rely on in vitro experiments using stable isotopes, to simulate the transfer of the corresponding radioactive nuclides from contaminated soil to plants and even to trace their path in the food chain (Choi et al. 2011).

We selected one experimental field in Changping district, China, because this is a major vegetablegrowing area in Beijing. The results seen in Figs. 1 and 4 are consistent with one fact, namely that the transfer of strontium from soil to the plant showed no linear relationship - whether it was to the above-ground parts or below-ground parts and whether it was to Chinese cabbage or to spinach. Constructing a regression equation based on experimental data enhances our understanding of the accumulation of strontium in these two kinds of vegetables. This method is of more practical significance than the transfer coefficients obtained from direct testing. As long as plants are grown in soil, they will absorb strontium without discriminating between its stable and radioactive forms. For example, samples of soil and plants collected from the sites of nuclear power plants or from nuclear test fields contain both stable and radioactive strontium. It is theoretically possible to obtain the relevant transfer coefficients by determining the contents of radioactive nuclides in soil and in the plants grown on that soil.

Different plant organs differed in their capacity to absorb or accumulate strontium, as can be seen in Figs. 1 and 2. The derivative value is different at each point along the curve. In order to better understand the pattern of transfer and accumulation of a nuclide in one plant, it is necessary to examine the transfer of both stable and radioactive nuclides simultaneously by adding radionuclides to soil.

Although it was a simulation, the data were obtained from actual experiments, a step that makes the resulting
Fig. 5 Correlation value ( $\delta$ ) between strontium and other elements in these two kinds of vegetable leaf and stem

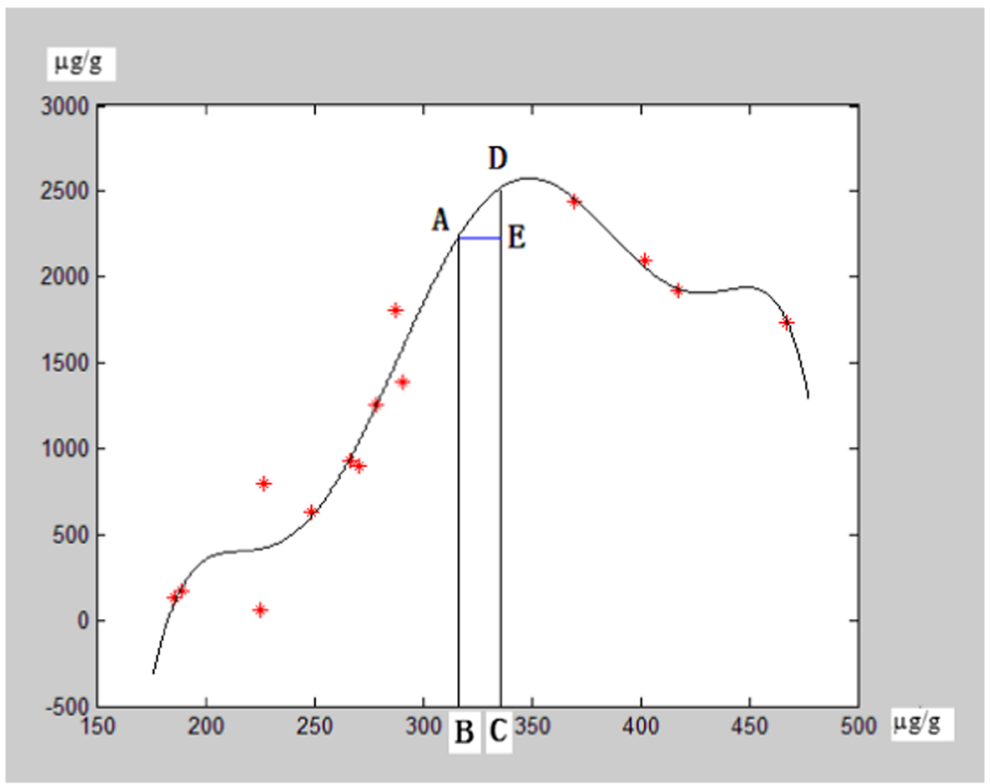


equations more meaningful. Such simulations not only avoid contamination of the environment by radioactive nuclides but also obviate the need to provide protection from radioactive nuclides in the laboratory. The constructed curves, regression equations, and their differential equations can help in understanding the process of transfer of radioactive nuclides from soil to plants and in assessing the potential hazards from such a transfer. In Fig. 1, for example, by taking a point (A) on the curve and connecting it to the horizontal axis by a straight vertical line, the corresponding value of the content of strontium can be estimated for a given location. Thus, we can predict the amount of nuclides likely to be transferred from soil to the plants by using this curve. In Fig. 5, nuclide concentration corresponding to the line $\mathrm{DE}$ is the amount of ${ }^{90} \mathrm{Sr}$ from soil transferred the stems and leaves of Chinese cabbage. From that value, we can calculate the content of ${ }^{90} \mathrm{Sr}$ in one individual based on the quantity of Chinese cabbage consumed by him or her. This can provide a theoretical basis for appropriate treatment by a physician. Therefore, this curve is of practical application in dealing with accidents in nuclear power. Apart from calculating the content of radioactive nuclides and internal radiation dose, we can also calculate these parameters by the equations and their differential equations, respectively.

As is shown in Figs. 1 and 3, strontium content of stems and leaves increased with strontium content in the soil but not always: at some point, it began to decrease (Fig. 3). These observations are consistent with those from the study by Li et al. (2004), which showed that low concentrations of strontium promote photosynthesis. However, when strontium concentration reaches $5 \mathrm{mmol} /$ $\mathrm{L}$, symptoms of toxicity begin to appear and chlorophyll content begins to fall, although it remains higher than that in the control group; the strontium content in the plant also begins to decrease. Although the vegetables we chose for the experiment were different from those chosen by Limei and co-workers, the patterns of strontium transfer and accumulation were similar.

The experimental curve, the corresponding regression equation, and the differential equation also have certain limitations. Strontium absorption by plants is affected by many factors such as the $\mathrm{pH}$ value of the soil, organic matter in the soil, types of metal ions and their existing forms, and the size of soil particles. We determined not only strontium but also other elements such as $\mathrm{Ca}, \mathrm{Fe}, \mathrm{Mg}, \mathrm{Na}, \mathrm{P}, \mathrm{K}$, and $\mathrm{S}$. Among these, $\mathrm{Na}$ and $\mathrm{S}$ showed the highest correlation with strontium in stems and leaves of Chinese cabbage and spinach and were followed by $\mathrm{Ca}$ and $\mathrm{Mg}$. In Chinese cabbage, the correlation between each of these elements and strontium was negative. In spinach, $\mathrm{Na}, \mathrm{S}$, and $\mathrm{Mg}$ all were negatively correlated with $\mathrm{Sr}$, and so was $\mathrm{Ca}$, a result different with earlier reports of a negative correlation between $\mathrm{Ca}$ and $\mathrm{S}$. This difference shows that the capacity of a plant to absorb strontium is not a simple sum of these individual factors but a result of interaction between them. Many experiments have shown that $\mathrm{Ca}$ and $\mathrm{Sr}$ share very similar characteristics in terms of their accumulation within the bodies of animals. Besides the interaction of various elements in soil, other factors also affect such accumulation of strontium, including the soil environment and plant species. By adding up all the $\mathrm{Sr}$ negative correlation value of stems and leaves about two kinds of vegetables, it was not difficult to calculate the sum of sigma for Chinese cabbage (besides the negative correlation value of $\mathrm{Ca}$ to $\mathrm{Sr}$ ) that is is close to $1, \Sigma$ sigma $=0.993569$; for spinach: $\Sigma$ sigma $=1.307831$. If all negative correlation values of $\mathrm{Ca}$ about Chinese cabbage to Sr were added up, the $\Sigma$ sigma $=1.120979$. For the spinach, if its negative correlation values were added up with its positive correlation value, then $\Sigma$ sigma $=1.307831+(0.18658+0.012704)=0.18658$. Therefore, this is almost the same about two data (1.120979 and 1.108547). These results suggest that there exists an optimum balance between the elements that have positive and negative effects. Whether $\mathrm{Ca}$ has a positive or a negative correlation with $\mathrm{Sr}$ in the process of its absorption depends not only on the contents of these elements but also on the functions of other elements. In the case of roots of Chinese cabbage and spinach, $\mathrm{Ca}$ and $\mathrm{Mg}$ showed the highest correlation with strontium. However, more research is needed to explain why $\mathrm{Mg}$ functioned differently in these experiments.

Acknowledgments This work was supported by grants from National Key Technology Research and Development Program of the Ministry of Science and Technology of China (No.2013BAK03B05).

\section{References}

Choi, Y. H., Lim, K. M., Jun, I., et al. (2009). Root uptake of radionuclides following their acute soil depositions during the growth of selected food crops [J]. Journal of Environmental Radioactivity, 100, 746-751. 
Choi, Y. H., Lim, K. M., Jun, I., et al. (2011). Transport behavior and rice uptake of radiostrontium and radiocesium in flooded paddy soils contaminated in two contrasting ways $[\mathrm{J}]$. Science of the Total Environment, 412, 248-256.

Höllriegl, V., Werner, E., Roth, P., Wendler, I., et al. (2002). Studies of strontium biokinetics in humans, Part 1: optimisation of intrinsic labelling of foodstuffs with stable isotopes of strontium [J]. Radiation and Environmental Biophysics, 41, 179-183.

James, J. P., Dileep, B. N., Ravi, P. M., et al. (2011). Soil to leaf transfer factor for the radionuclides ${ }^{226} \mathrm{Ra}, 40 \mathrm{~K},{ }^{137} \mathrm{Cs}$ and ${ }^{90} \mathrm{Sr}$ at Kaiga region, India [J]. Journal of Environmental Radioactivity, 102, 1070-1077.
Mei, L., Jin, X., ZhiLi, L., et al (2004). The impact on dicrateria inornate came from the oxidative stress induced by Sr. [J]. Oceans and Lakes, 35(5), 467-472.

Mollah, A. S., Begum, A., \& Ullah, S. M. (1998). Determination of soil-to-plant transfer factors of ${ }^{137} \mathrm{Cs}$ and ${ }^{90} \mathrm{Sr}$ in the tropical environment of Bangladesh [J]. Radiation and Environmental Biophysics, 37, 125-128.

Tatiana, G., Levitskaia, J. A., Creim, T. L., et al. (2010). Biomaterials for the decorporation of ${ }^{85} \mathrm{Sr}$ in the rat[J]. Health Physics, 99(3), 394-400.

Tolstykh, E. I., Degteva, M. O., Peremyslova, L. M., et al. (2013). Reconstruction of long-lived radionuclide intakes for techa riverside residents ${ }^{137} \mathrm{Cs}[\mathrm{J}]$. Health Physics, 104(5), 481-498. 